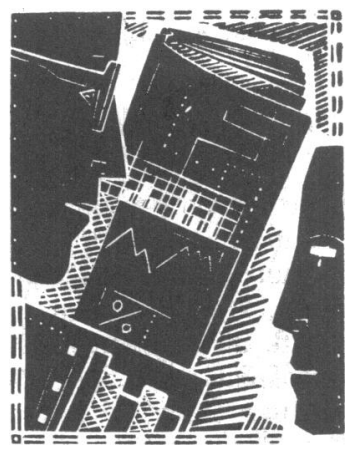

\title{
Improving care: a study of orthopaedic outpatient referrals
}

\author{
M O Roland, R W Porter, J G Matthews, J F Redden, G W Simonds, B Bewley
}

\section{Abstract}

Objective-To identify aspects of outpatient referral in which general practitioners', consultants', and patients' satisfaction could be improved.

Design-Questionnaire survey of general practitioners, consultant orthopaedic surgeons, and patients referred to an orthopaedic clinic.

Setting-Orthopaedic clinic, Doncaster Royal Infirmary.

Subjects -628 consecutive patients booked into the orthopaedic clinic.

Main outcome measures-Views of the general practitioners as recorded both when the referral letter was received and again after the patient had been seen, views of the consultants as recorded at the time of the clinic attendance, and views of the patients as recorded immediately after the clinic visit and some time later.

Results-Consultants rated 213 of 499 referrals $(42.7 \%)$ as possibly or definitely inappropriate, though 373 of 451 patients $(82 \cdot 7 \%)$ reported that they were helped by seeing the consultant. Targets for possible improvement included information to general practitioners about available services, communication between general practitioners and consultants, and administrative arrangements in clinics. Long waiting times were a problem, and it seemed that these might be reduced if general practitioners could provide more advice on non-surgical management. Some general practitioners stated that they would value easier telephone access to consultants for management advice. It was considered that an alternative source of management advice on musculoskeletal problems might enable more effective use to be made of specialist orthopaedic resources.

Conclusion-A survey of patients' and doctors' views of referrals may be used to identify aspects in which the delivery of care could be made more efficient. Developing agreed referral guidelines might help general practitioners to make more effective use of hospital services.

School of Clinical

Medicine, Addenbrooke's Hospital, Cambridge CB2 200

$M$ O Roland, DM, director of studies in general practice

Doncaster Royal Infirmary, Doncaster DN2 5LT

R W Porter, MD, consultant orthopaedic surgeon

J G Matthews, FRCS, consultant orthopaedic surgeon J F Redden, FRCS, consultan orthopaedic surgeon

G W Simonds, MCH ORTH, consultant orthopaedic surgeon B Bewley, research assistant

Correspondence to:

Dr Roland.

BMF 1991;302:1124-8 be to focus attention on the value of hospital referrals. From the general practitioners' point of view health authorities, as purchasers of health care, will require feedback from general practitioners in order to determine where to place contracts. In areas where there are several competing hospitals certain aspects of quality of care-for example, waiting lists-may have an important effect on where contracts are placed. In turn, general practitioners will be encouraged to look at their own performance in relation to referral, ${ }^{2}$ which is likely to be an important subject addressed by medical audit advisory committees. Finally, the views of patients about the care provided will become increasingly important, family health services authorities having specific responsibility to seek the views of patients on services provided.

The present survey had two main aims: to seek the views of general practitioners, consultants, and patients on the operation of the orthopaedic clinic at Doncaster Royal Infirmary, and to make recommendations on improvements to the service, focusing particularly on those which could be achieved within existing resources.

\section{Method}

Patients referred by general practitioners to the orthopaedic outpatient clinic at Doncaster Royal Infirmary between 11 September and 1 December 1989 were enrolled into the study. Patients were included only if they were new referrals or if they had been rereferred with a new letter from their general practitioner. With the exception of three clinics during which the registrar stood in for the consultant at the last minute, patients were excluded if they saw a doctor other than one of the four consultants at their clinic attendance. Patients who saw the registrar had already been enrolled into the study and were therefore included. No patient was enrolled into the study on more than one occasion.

When the general practitioner's letter was received at the hospital he or she was sent a questionnaire asking for his or her opinions on the reasons for making the referral, how necessary he or she thought the referral was, how much pressure had been applied by the patient to make the referral, and whether the provision of other facilities might have prevented the referral. The intention was to send these questionnaires to the general practitioners shortly after the referral letter arrived at the hospital. When the research assistant started work, however (six months before the first clinic), roughly a third of patients were already booked into the study clinics, so that some general practitioners received their questionnaires several months after they had made the referral. The research assistant generally checked the clinic lists during the working day before the day of a clinic. Some patients who were referred as a matter of urgency and who were seen on the day of referral or the next day may therefore not have been included in the study.

When the patient attended the clinic the consultant completed a questionnaire including details of procedures carried out at or arranged from the clinic. He then assessed the appropriateness of the referral as 
“definitely appropriate," "possibly inappropriate," or "definitely inappropriate." $\mathrm{He}$ was asked to give reasons if he judged the referral possibly or definitely inappropriate. The consultant was then asked to judge whether, in his opinion, the patient exhibited "inappropriate pain behaviour."

On leaving the clinic patients were approached by the research assistant, who explained the study. They completed a very brief questionnaire at that time, which asked whether they thought that they had been helped by seeing the specialist and whether they thought that their general practitioner could have managed without a referral. They were then given a second, more detailed questionnaire to return by post in a stamped addressed envelope. That questionnaire asked for details of the patient's satisfaction with the clinic, with particular emphasis on communication with the consultant - for example, whether enough time had been given, and whether the patient was satisfied with the consultant's explanation of the problem or treatment, or both. Space was included in the second questionnaire for free text comments to be added. Details of the patients' and (for married women) spouses' occupations were collected for analysis of the social class distribution of the sample (Office of Population Censuses and Surveys classification).

The second questionnaire to the referring general practitioner was sent with the consultant's reply, which was invariably sent out within a week of the clinic. Questions included how useful the referral had been to the general practitioner or to his or her patient, whether the delay was acceptable, whether the information in the consultant's letter was adequate, and whether, in retrospect, the provision of other facilities might have prevented the referral.

In the case of patients who failed to attend for their clinic appointment a questionnaire was sent to both patient and referring general practitioner asking for reasons for non-attendance. Response rates of over $90 \%$ were achieved for all the questionnaires with the exception of the second patient questionnaire and the questionnaire to patients who did not keep their appointment.

The figure shows the overall design of the study, along with response rates to the questionnaires. Completed questionnaires were sent to Cambridge for data entry, verification, and subsequent analysis on Cambridge University's mainframe computer by using the statistical package for the social sciences $\mathrm{X}$. The program Hiloglinear was used to construct log linear models for analyses including interacting variables.

\section{Results}

\section{GENERAL PRACTITIONERS' FIRST QUESTIONNAIRE}

General practitioners returned $591(94 \cdot 1 \%)$ of the 628 first questionnaires (figure) and reported that they were "completely certain" about the diagnosis in 313 cases $(53.0 \%)$. The commonest reason given for making the referral was "for advice on management" (349 cases; $59 \cdot 1 \%)$. In 120 cases $(20 \cdot 3 \%$ ) the general practitioner reported that his or her decision to refer had been influenced "quite a lot" or "very greatly" by pressure from the patient.

Table I lists the general practitioners' responses to

TABLE I-General practitioners' perceptions of need for referral (591/628 questionnaires returned; $94 \cdot 1 \%$ )

\begin{tabular}{lccccccc}
\hline & \multicolumn{5}{c}{ "How necessary do you think it is for this patient to see a specialist?" } \\
\cline { 2 - 7 } & $\begin{array}{c}\text { Absolutely } \\
\text { necessary }\end{array}$ & $\begin{array}{c}\text { Probably } \\
\text { necessary }\end{array}$ & $\begin{array}{c}\text { Probably } \\
\text { unnecessary }\end{array}$ & $\begin{array}{c}\text { Definitely } \\
\text { unnecessary }\end{array}$ & $\begin{array}{c}\text { No } \\
\text { response }\end{array}$ & Total \\
\hline No $(\%)$ of general practitioners & $186(31 \cdot 5)$ & $323(54 \cdot 7)$ & $51(8 \cdot 6)$ & $13(2 \cdot 2)$ & $18(3 \cdot 0)$ & $591(100 \cdot 0)$ \\
\hline
\end{tabular}

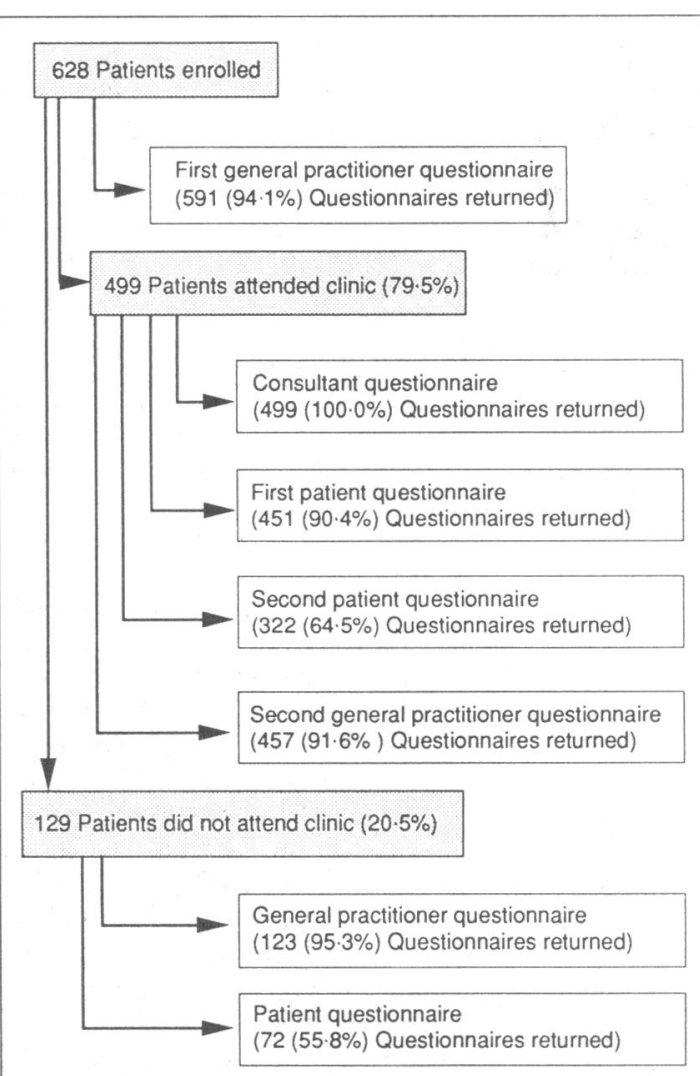

Design of study and response rates.

the question, "How necessary do you think it is for this patient to see a specialist?" In 64 cases $(10.8 \%)$ the general practitioner thought that the referral was probably or definitely unnecessary. Referrals for back pain were most likely to be judged unnecessary, and the referral was particularly likely to be judged unnecessary if the general practitioner reported substantial patient pressure to be referred $(22 \cdot 7 \%$ of referrals $(27 / 119)$ in which general practitioners reported that they had been influenced "quite a lot" or "greatly" to make the referral, compared with $8 \cdot 2 \%$ of other referrals (37/453); difference $14 \cdot 5 \%$ (95\% confidence interval $6 \cdot 6 \%$ to $22 \cdot 4 \%$ )).

In 58 cases the general practitioner indicated that provision of another facility might have prevented a referral, those mentioned including direct access to the appliance department ( 24 cases), access to physiotherapy or to the back school (nine cases), access to chiropody, and easier telephone access to consultants among other possible facilities. Some of these facilities were available to Doncaster general practitioners, and it was not clear from the replies whether general practitioners were unaware of the access that they had or whether difficulties in arranging the facilities made them decide to refer the patient.

\section{CLINIC PROCEDURES}

A total of 499 of the 628 patients enrolled in the study $(79.5 \%)$ attended the clinic. The median waiting time to see the consultant from the date of receipt of the general practitioner's letter was 24 weeks (range 1-76 weeks). Some patients with very long waiting times had cancelled an earlier appointment and been offered one at a later date. At the clinic physiotherapy was arranged for 52 patients $(10 \cdot 4 \%), 34$ patients $(6 \cdot 8 \%)$ received an injection, $133(26 \cdot 7 \%)$ had radiography, $81(16 \cdot 2 \%)$ received a follow up appointment, and 81 $(16 \cdot 2 \%)$ were put on a waiting list for surgery at their initial clinic attendance. Follow up rates for the four consultants varied from $2 \cdot 2 \%$ ( $3 / 135$ patients) to $41 \cdot 7 \%$ $(43 / 103)$, and the proportion of patients put on a 
waiting list for surgery at the initial consultation varied from $6 \cdot 8 \%(7 / 103)$ to $24 \cdot 4 \%(30 / 123)$ among the four consultants. For all major diagnostic groups (spine, shoulder, arm, hip, knee, ankle, and foot) there were greater than twofold differences in follow up and surgery waiting list rates among the four consultants, and the differences in follow up rates remained highly significant after controlling for diagnostic group (partial $\left.\chi_{3}^{2}=76 \cdot 6 ; \mathrm{p}<0 \cdot 001\right)$.

\section{CONSULTANTS' QUESTIONNAIRE}

Consultants judged $213(42 \cdot 7 \%)$ of the 499 referrals to be possibly or definitely inappropriate (table II) Judgment about whether a referral was possibly or definitely inappropriate was subjective, and we did not set any criteria for the consultants to follow. There were many instances in which the views of the people concerned might have differed - for example, a young woman with an exostosis on her foot who had a problem only because she wished to wear fashionable shoes. The commonest reason given for judging a referral inappropriate was that the "general practitioner should have treated this problem" (114 cases; $53 \cdot 5 \%$ ). Consultants were somewhat intolerant of patients who had got better, of those who required reassurance alone, of patients who could have been referred directly to physiotherapy, those with ingrowing toenails (all referred to chiropody), or patients with ganglia (rarely judged appropriate). A common comment was "I have done nothing the general practitioner could not have done," which emphasised that the consultants wished that the general practitioners had more skill or confidence in non-surgical management.

Patients with back pain, children, and those whose complaint was judged to be non-organic were least likely to be rated as appropriate, but a wide variety of diagnoses were included in those rated as inappropriate. Those with hip problems were most likely to be rated as appropriate. One consultant ran a clinic for spinal disorders, and he saw nearly half of all the patients with back pain in the study. Patients with back problems were more likely to be rated as appropriate if they saw the consultant with a special interest in spinal disorders than if they saw one of the other consultants.

TABLE II-Consultants' perceptions of appropriateness of referrals (questionnaires returned on all 499 patients who attended clinic)

\begin{tabular}{lcccccc}
\hline & \multicolumn{4}{c}{ "Doyou think the referral was definitely appropriate or possibly or definitely inuppropriate?" } \\
\cline { 2 - 7 } & $\begin{array}{c}\text { Definitely } \\
\text { appropriate }\end{array}$ & $\begin{array}{c}\text { Possibly } \\
\text { inappropriate }\end{array}$ & $\begin{array}{c}\text { Definitely } \\
\text { inappropriate }\end{array}$ & $\begin{array}{c}\text { No } \\
\text { response }\end{array}$ & Total \\
\hline No $(\%)$ of consultants & $284(56 \cdot 9)$ & $152(30 \cdot 5)$ & $61(12 \cdot 2)$ & $2(0 \cdot 4)$ & $499(100 \cdot 0)$ \\
\hline
\end{tabular}

TABLE III-Patients' perceptions of value of clinic attendance (451/499 patients who returned first questionnaire; $90 \cdot 4 \%$ )

\begin{tabular}{lccccccc}
\hline & \multicolumn{5}{c}{ "Do you think you have been helped by seeing the specialist?" } \\
\cline { 2 - 7 } & $\begin{array}{c}\text { Definitely } \\
\text { helped }\end{array}$ & $\begin{array}{c}\text { Probably } \\
\text { helped }\end{array}$ & $\begin{array}{c}\text { Not } \\
\text { sure }\end{array}$ & $\begin{array}{c}\text { Probably not } \\
\text { helped }\end{array}$ & $\begin{array}{c}\text { Definitely not } \\
\text { helped }\end{array}$ & Total \\
\hline No $(\%)$ of patients & $294(65 \cdot 2)$ & $79(17 \cdot 5)$ & $40(8 \cdot 9)$ & $22(4 \cdot 9)$ & $16(3 \cdot 5)$ & $451(100 \cdot 0)$ \\
\hline
\end{tabular}

TABLE IV-Relation between general practitioners' perceptions of necessity for referral and consultants' perceptions of its appropriateness (457 cases in which this section of both questionnaires was completed). Results expressed as numbers (percentages) of referrals

\begin{tabular}{lrrrrr}
\hline & \multicolumn{5}{c}{ General practitioners' judgment } \\
\cline { 2 - 6 } Consultants' judgment & $\begin{array}{c}\text { Absolutely } \\
\text { necessary }\end{array}$ & $\begin{array}{c}\text { Probably } \\
\text { necessary }\end{array}$ & $\begin{array}{c}\text { Probably } \\
\text { unnecessary }\end{array}$ & $\begin{array}{c}\text { Definitely } \\
\text { unnecessary }\end{array}$ & Total \\
\hline Definitely appropriate & $101(64 \cdot 7)$ & $136(54 \cdot 8)$ & $18(41 \cdot 9)$ & $5(50 \cdot 0)$ & $260(56 \cdot 9)$ \\
Possibly inappropriate & $38(24 \cdot 4)$ & $78(31 \cdot 5)$ & $20(46 \cdot 5)$ & $3(30 \cdot 0)$ & $139(30 \cdot 4)$ \\
Definitely inappropriate & $17(10 \cdot 9)$ & $34(13 \cdot 7)$ & $5(11 \cdot 6)$ & $2(20 \cdot 0)$ & $58(12 \cdot 7)$ \\
\hline Total & $156(100 \cdot 0)$ & $248(100 \cdot 0)$ & $43(100 \cdot 0)$ & $10(100 \cdot 0)$ & $457(100 \cdot 0)$ \\
\hline
\end{tabular}

$\gamma_{h}^{2}=10 \cdot 4 ; p=0 \cdot 11$
Consultants were much less likely to judge a referral as appropriate if they thought that a patient was displaying inappropriate pain behaviour (34 of 49 patients $(69 \cdot 4 \%)$ displaying inappropriate pain behaviour were judged as inappropriate referrals compared with 175 of 444 patients $(39.4 \%)$ who did not display this behaviour; difference $30 \%$ (95\% confidence interval $16 \cdot 4 \%$ to $43 \cdot 6 \%)$ ).

\section{PATIENTS' QUESTIONNAIRES}

Most of the 451 patients $(90.4 \%)$ who completed the first questionnaire thought that they had been helped by seeing the specialist (table III). Responses to the questions were not significantly related to age, sex, or social class. Patients were significantly less likely to perceive that they had been helped if they presented with back pain. (81 of 116 patients $(69.8 \%)$ with back pain definitely or probably helped compared with 292 of 335 patients $(87 \cdot 2 \%)$ with other diagnoses; difference $17 \cdot 2 \%(95 \%$ confidence interval $8 \cdot 1 \%$ to $24 \cdot 3 \%)$ ).

A total of 322 patients $(64.5 \%)$ returned the second questionnaire. Of these, $185(57 \cdot 5 \%)$ gave "to find out what is wrong" as their commonest reason for attending the clinic. Other reasons were "to discuss an operation or some other way of getting better" (121 patients; $37.6 \%)$ and "to be quite sure there is nothing really serious wrong" $(114 ; 35 \cdot 4 \%)$. Forty five patients $(14.0 \%)$ gave "to be quite sure there is nothing really serious wrong" as their sole reason for attending the clinic.

The commonest complaints about the clinic (from the second questionnaire) were the long waiting time for appointments and long waits in the clinic. Seventy three of the 322 patients $(22 \cdot 7 \%)$ complained of insufficient time with the specialist and $111(34 \cdot 5 \%)$ reported that they had not been able to say all they wanted to the specialist. Of 249 patients who said that they wanted an explanation of their problem, 60 $(24 \cdot 1 \%)$ were dissatisfied with the explanation; and of 155 patients who said that they wanted an explanation of their treatment, $42(27 \cdot 1 \%)$ were dissatisfied with the explanation.

\section{GENERAL PRACTITIONERS' SECOND QUESTIONNAIRE}

General practitioners returned 457 of the 499 second questionnaires $(91 \cdot 6 \%)$. In 364 instances $(79 \cdot 6 \%)$ these showed that the doctor was satisfied or very satisfied with the attention that the patient had received at the hospital, but in 202 instances $(44 \cdot 2 \%)$ doctors judged that the waiting time had been unreasonable. They were least satisfied with referrals for back pain, 23.6\% of which ( 26 of 110$)$ were judged to have been "not very useful" or "useless" to the patient or the general practitioner.

In 216 cases $(47 \cdot 3 \%)$ the general practitioner found that the information supplied by the consultant was "very helpful," but in 38 cases $(8.3 \%)$ the information was "rather inadequate" or "completely inadequate." Specific comments related to lack of prognostic information in consultants' letters and lack of information that would help the general practitioner in his or her future management of the patient.

RELATION BETWEEN VIEWS OF GENERAL PRACTITIONERS, CONSULTANTS, AND PATIENTS

There was a poor relation between the general practitioner's view of how necessary the referral was and the consultant's perception of its appropriateness (table IV). Indeed, $43 \%$ of referrals $(23 / 53)$ rated as "probably or totally unnecessary" by the general practitioner were thought to be "definitely appropriate" by the consultant. Relations between the consultants' and patients' views were somewhat more clear cut. Patients were much more likely to report that they had been helped by the referral when the 
consultant rated the referral as appropriate (table V). There were, however, cases in which the perceptions of the three parties clearly differed. For example, in a man with a ganglion the general practitioner reported a lot of pressure to refer, the consultant rated the referral as "possibly inappropriate" as the patient did not wish to have surgery, but the patient commented, "It was very helpful and useful. I was very satisfied.’

\section{Discussion}

The aim of this study was to see whether a questionnaire survey could be used to identify ways in which the specialist orthopaedic service in Doncaster could be improved without providing additional resources. After analysis of the questionnaires the results were circulated to the orthopaedic consultants and a lunchtime meeting arranged at Doncaster Royal Infirmary. This was attended by three of the consultants and about 35 general practitioners. The practical issues for possible change identified in this part of the paper arose both from the survey and from the meetings which followed.

Given that the long waiting list was the commonest complaint of both patients and general practitioners, and that the specialists rated a substantial proportion of referrals as inappropriate, part of our discussion focuses on whether general practitioners could refer fewer patients to hospital without reducing the quality of patient care. Our analysis of the appropriateness of the referrals was based solely on the opinion of the consultant after seeing the patient. Previous work has shown that consultants, general practitioners, and patients may have very different perceptions of the purpose and value of a referral, ${ }^{45}$ and this was evident in our study. In some areas general practitioners and specialists have worked together to produce guidelines for the types of problem that should be referred. ${ }^{6}$ If agreed referral guidelines had been available in Doncaster it would have been possible to use the guidelines as a standard by which to judge the referrals and thus undertake a more detailed and objective analysis of the appropriateness of the referrals. The development of such guidelines is one way in which general practitioners might be helped to make more effective use of hospital resources.

\section{ASPECTS FOR POSSIBLE CHANGE}

Ten main aspects for possible change were identified.

(1) For a large number of referrals the main role of the consultant was to provide management advice, with no need for hospital based investigation or treatment. Improvement in general practitioners' orthopaedic management skills could reduce some of these referrals.

(2) General practitioners may be unaware of facilities to which they have access. Some seemed unaware that they had unrestricted access to the physiotherapy department and that this could be used as a route to the back school. General practitioners do not have direct

TABLE $\mathrm{v}-$ Relation between consultants' perceptions of appropriateness of referral and patients' perceptions of having been helped (449 cases in which both questionnaires were completed). Results expressed as numbers (percentages) of referrals

\begin{tabular}{lcccc}
\hline & \multicolumn{4}{c}{ Consultants' judgment } \\
\cline { 2 - 5 } Patients' judgment & $\begin{array}{c}\text { Definitely } \\
\text { appropriate }\end{array}$ & $\begin{array}{c}\text { Possibly } \\
\text { inappropriate }\end{array}$ & $\begin{array}{c}\text { Definitely } \\
\text { inappropriate }\end{array}$ & Total \\
\hline Definitely helped & $195(73 \cdot 9)$ & $76(57 \cdot 1)$ & $21(40 \cdot 4)$ & $292(65 \cdot 0)$ \\
Probably helped & $41(15 \cdot 5)$ & $26(19 \cdot 5)$ & $12(23 \cdot 1)$ & $79(17 \cdot 6)$ \\
Not sure & $19(7 \cdot 2)$ & $14(10 \cdot 5)$ & $7(13 \cdot 5)$ & $40(8 \cdot 9)$ \\
Probably not helped & $6(2 \cdot 3)$ & $12(9 \cdot 0)$ & $4(7 \cdot 7)$ & $22(4 \cdot 9)$ \\
Definitely not helped & $3(1 \cdot 1)$ & $5(3 \cdot 8)$ & $8(15 \cdot 4)$ & $16(3 \cdot 6)$ \\
\hline Total & $264(100 \cdot 0)$ & $133(100 \cdot 0)$ & $52(100 \cdot 0)$ & $449(100 \cdot 0)$ \\
\hline
\end{tabular}

$x_{\dot{s}}=47.5 ; \mathrm{p}<0.001$ access to the appliance department, but if a request for an appliance is made in an informative letter the consultant will often refer the patient directly to the appliance department without booking a formal outpatient appointment. Some general practitioners were unaware that they had direct access to the pain clinic. Information about available facilities might enable some general practitioners to choose more appropriate referral pathways.

(3) There are some practical procedures which could be undertaken by general practitioners - for example, joint injections and treatment of ingrowing toenails, which together accounted for $68(13 \cdot 6 \%)$ of the clinic referrals in this series. There are now financial incentives for general practitioners to carry out these procedures in their surgeries, and there are also incentives (relating to the postgraduate education allowance) for practices, or groups of practices, to invite specialists to visit their practices to demonstrate techniques such as joint injection.

(4) General practitioners do not have access to chiropody services for most adults, but all ingrowing toenails were referred to the hospital chiropodist by the orthopaedic surgeons, usually after a long wait for a clinic appointment. This may be avoided by direct referral for chiropody by the consultants on receipt of an appropriate letter. Alternatively general practitioners could be given direct access to the chiropody department for specified conditions.

(5) General practitioners would value easier telephone access to consultants to discuss clinical problems. This may reduce the need for some referrals, and in one study a substantial proportion of referrals were dealt with by telephone. ${ }^{?}$ The consultants have now instituted a regular time when they will be available for telephone consultation with general practitioners - for half an hour on each of the four weekdays-and this new service is currently being evaluated.

(6) In almost one fifth of cases the general practitioner was under pressure to refer. Overrepresented among these were patients who stated that what they wanted was reassurance that nothing serious was wrong. In some cases it seemed that the general practitioner had not made the reason for referral clear in the letter. A more carefully phrased referral letter might help the consultant to understand the reason for referral and help the consultant to satisfy patients' expectations of the consultation.

(7) Coupled with the consultants' complaints that general practitioners should have been able to manage many of the referrals were the general practitioners' complaints that they were given insufficient advice on management in the consultants' letters. It was noted that some letters (in both directions) were unusually short, and further analysis of these is currently being undertaken. Many of the patients rated by the consultants as "inappropriate" had chronic problems, and in this setting a letter from a specialist giving detailed practical advice can, if the advice is followed, empower the general practitioner to keep the patient going for many consultations.

(8) The waiting time in clinics was a major source of concern to patients and should be reviewed. The patients of one of the consultants were much less likely to complain of long waits in the clinic than other patients. That consultant had a very organised clinic and did not add urgent patients to clinics which were already booked, preferring to make alternative arrangements for them. Although his patients were less likely to complain of long waits, they were more likely to complain of insufficient time with the doctor. Keeping a clinic running efficiently to time may mean that some patients spend less time with the doctor than they would wish. 
(9) Several complaints about administration of the commercial appliance department seemed justifiedfor example, being asked to attend when the department was closed. Long waits were also a common complaint about the appliance department, and these problems require further investigation.

(10) Patients who had got better by the time they attended the clinic were rarely regarded as appropriate referrals by the consultants. It might be possible to include in the patient's initial appointment a note to indicate that patients should consult their general practitioner if their symptoms were resolved by the clinic date, with a view to cancelling the appointment. Consideration might also be given to contacting patients who had been on the waiting list for many weeks to find out whether they still needed to attend.

\section{CHANGES SUGGESTED AS A RESULT OF THE SURVEY}

The changes suggested as a result of this survey fall under four main headings. Firstly, general practitioners might improve their skills in managing certain orthopaedic problems. The training of general practitioners in orthopaedics has been criticised, and several studies have aimed at improving matters by using educational interventions, but with only limited success. $^{x-11}$ Emmanuel and Walter have described a general strategy for improving the appropriateness of referrals, with general practitioners and consultants meeting to discuss guidelines for referral. ${ }^{6}$ This approach is being adopted nationally by the Dutch College of General Practitioners. ${ }^{12}$ A dialogue between Doncaster general practitioners and orthopaedic consultants about the appropriateness of referrals would be greatly assisted by the development of clear referral guidelines. An alternative strategy would be to provide a different source of management advice for musculoskeletal problems - for example, an associate specialist in physical medicine who would refer on to the consultant orthopaedic surgeon only those patients requiring surgery.

Secondly, improved information may help general practitioners to choose more appropriate referral pathways. Thirdly, improved administrative arrangements might lead to shorter waiting times in clinics and other departments. Finally, we have identified several issues in which poor communication leads to dissatisfaction with the referral process-including referrals in which the general practitioner has not made the reason for referral clear to the consultant, consultants' letters which are insufficiently informative, and dissatisfaction with communication within the clinic, particularly by patients regarded by the consultant as inappropriately referred. In addition, some general practitioners expressed a need for easier telephone access to consultants for advice.

We have shown that questionnaires to general practitioners, patients, and consultants can be used to identify parts of the referral process in which improvements could be made. We employed a research assistant partly because of the large amount of data collected on each patient and partly because we wished to ensure a high response rate to the questionnaires. It would, however, be possible to collect more limited data without employing extra staff, and the method described clearly has potential for identifying areas where quality of care within the NHS can be improved.

We are grateful to Mrs Jean Reynolds for help in administering the study and to Doncaster health authority and the orthopaedic department at Doncaster Royal Infirmary, which funded the study.

1 Secretaries of State for Health, Wales, Northern Ireland, and Scotland. Working for patients. London: HMSO, 1989. (Cmnd 555.)

Health Departments of Great Britain. General practice in the National Health Service: the 1990 contract. London: Health Departments of Great Britain, 1989

3 Office of Population Censuses and Surveys. Classification of occupations 1980. London: HMSO, 1980.

+ Grace JF, Armstrong D. Reasons for referral to hospital: extent of agreement between the perceptions of patients, general practitioners and consultants. between the perceptions of

5 Grace JF, Armstrong D. Referral to hospital: perceptions of patients, general practitioners and consultants about necessity and suitability of referral. practitioners and consultan

6 Emmanuel J, Walter N. Referrals from general practice to hospital outpatient departments: a strategy for improvement. BMF 1989;299:722-4.

7 Hartog M. Medical outpatients. F R Coll Physicians Lond 1988;22:51

8 Griffin GA, Kaneti-Barry SM. Muscle and joint pain: design and evaluation of courses for general practitioners. I $R$ Coll Gen Pract 1981;31:661-8.

9 Ross AK, Lawton WA. Evaluation of a course for general practitioners on muscles and joints. BMF 1984;28\%:609-12.

10 Grahame R, Gibson T, Dale E, el al. An evaluated programme of rheumatology training for general practitioners. Br f Rheumatol 1986;25:7-12.

11 Huston GJ. An offer of rheumatology training: failure to influence clinic referrals. BM7 1988:296:1773-4.

12 Grol R. National standard setting for quality of care in general practice: attitudes of general practitioners and response to a set of standards. British Journal of General Practice 1990:40:361-4.
Department of Public Health Medicine, United Medical and Dental Schools, St Thomas's Campus, London SE1 7EH M C Gulliford, MRCP, Wellcome Trust training fellow A Petruckevitch, MSC, lecturer in medical statistics P G J Burney, FFPHM, reader in public health medicine

Correspondence to: $\mathrm{Dr}$ Gulliford.

\section{Hospital case notes and medical audit: evaluation of non-response}

\author{
M C Gulliford, A Petruckevitch, P G J Burney
}

Written accounts of patients' treatment are widely used in medical audit. ${ }^{1-3}$ The Report of the Confidential Enquiry into Perioperative Deaths recently drew attention to the difficulty of obtaining patients' case notes but did not show whether non-response could bias the results of audit. ${ }^{4}$ We recently completed a multidistrict study in which we collected data by reviewing case notes. We evaluated whether non-response was systematic and a potential source of bias.

\section{Methods and results}

We studied the records of 609 men aged less than 75 who were resident in the South Thames regions and registered at the Thames Cancer Registry with bladder cancer in 1982. The patients' case notes and radiotherapy records were sought at the hospital(s) at which they were treated. Clinicians gave permission before case notes were obtained. The retrieval of each set of case notes was considered as a binomial trial. The associations of explanatory variables with retrieval were estimated by using logistic regression. ${ }^{5}$ The following variables (categories) were included in analyses: survival (alive, dead); year of death (years 1982-9, not deceased); district of residence (28 districts); region of residence (two regions); teaching status of hospital (undergraduate teaching hospital, other). We tested the significance of associations using the deviance difference as an approximate $\chi^{2}$ statistic. Confidence intervals for odds ratios were estimated.

The retrieval rate of hospital notes was lower for deceased patients than for surviving patients (table). The associations of other variables with retrieval of case notes varied between surviving and deceased patients so analyses were performed separately for the two groups. For surviving patients the response rate varied significantly with district of residence; retrieval rates from individual districts ranged from $38 \%$ to 